IZADP No. 1967

Is There a Social Security Tax Wedge?

Alessandro Cigno

February 2006 


\title{
Is There a Social Security Tax Wedge?
}

\author{
Alessandro Cigno \\ University of Florence, CESifo, CHILD \\ and IZA Bonn
}

Discussion Paper No. 1967

February 2006

\author{
IZA \\ P.O. Box 7240 \\ 53072 Bonn \\ Germany \\ Phone: +49-228-3894-0 \\ Fax: +49-228-3894-180 \\ Email: iza@iza.org
}

\begin{abstract}
Any opinions expressed here are those of the author(s) and not those of the institute. Research disseminated by IZA may include views on policy, but the institute itself takes no institutional policy positions.

The Institute for the Study of Labor (IZA) in Bonn is a local and virtual international research center and a place of communication between science, politics and business. IZA is an independent nonprofit company supported by Deutsche Post World Net. The center is associated with the University of Bonn and offers a stimulating research environment through its research networks, research support, and visitors and doctoral programs. IZA engages in (i) original and internationally competitive research in all fields of labor economics, (ii) development of policy concepts, and (iii) dissemination of research results and concepts to the interested public.
\end{abstract}

IZA Discussion Papers often represent preliminary work and are circulated to encourage discussion. Citation of such a paper should account for its provisional character. A revised version may be available directly from the author. 
IZA Discussion Paper No. 1967

February 2006

\title{
ABSTRACT
}

\section{Is There a Social Security Tax Wedge?}

\begin{abstract}
A Beveridgean pension scheme invariably introduces a wedge between the wage rate and the marginal take-home pay. A Bismarckian one can do so only if it is not actuarially fair, or in the presence of credit rationing. Interestingly, if the two possible sources of distortion are present at the same time, they will tend to offset each other. The distortion may even change sign (the wedge may become a premium). In any case, the same pension contribution will discourage labour less if the scheme is Bismarckian, than if it is Beveridgean.
\end{abstract}

JEL Classification: $\quad \mathrm{H} 31, \mathrm{H} 55, \mathrm{~J} 38$

Keywords: $\quad$ tax wedge, Bismarck, Beveridge, public pensions, implicit pension tax, labour

Corresponding author:

Alessandro Cigno

Dipartimento di Studi sullo Stato

Via delle Pandette 21

I-50127 Firenze

Italy

Email: cigno@unifi.it 


\section{Introduction}

The political discussion on the effects of pension policy appears to take it for granted that a pension contribution is a tax on labour income, and will thus discourage labour. Indeed, a series of empirical studies finds a negative effect of pension contributions on either employment or labour participation. See, for example, Alesina and Perotti (1997), Scarpetta (1996), Tullio (1987). The assumption is justified, and the empirical finding unsurprising, in countries that have given themselves a Beveridgean pension system, because individual pension benefits are then unrelated to individual contributions, and the latter are effectively an earmarked tax (the social security tax). Not so, however, in countries where the pension system is essentially Bismarckian, and thus characterized by a close link between benefits and contributions. In such countries, pension contributions are a form of mandatory saving, and we can talk of a pension tax only to the extent that pension contributions are higher than would be required to obtain the same amount of retirement income by other means.

The concept of an implicit pension tax appears to have been originally developed in Lüdeke (1988) and Sinn (1990). More recently, Murphy and Welch (1998) and Orszag and Stiglitz (2000) have come round to the idea. This theoretical insight has sparked-off a number of empirical studies aimed at measuring the tax component of pension contributions; see, for example, Börsch-Supan and Reil-Held (2001), and Fenge and Werding (2004). Disney (2004) takes the empirical analysis further by attempting to estimate the labour effects of the tax and the mandatory saving components of pension contributions. The author finds that, if the tax component is not controlled for, pension contributions reduce participation as in the earlier empirical studies mentioned. But, if both the tax and the saving component are used as explanatory variables, the former has a negative, and the latter a positive, effect on female participation (male participation appears to be insensitive to either).

The present note has the limited objective of deriving analytically the tax wedge associated with compulsory participation in a public pension scheme, and the consequent effect on the amount of time worked. It is shown that, while a contribution to a Beveridgean scheme will always introduce a wedge between the wage rate and the marginal take-home pay, a Bismarckian scheme may do so only if the scheme is not actuarially fair, or in the presence of credit rationing. Interestingly, if the two

possible sources of distortion are present at the same time, they will tend to offset each other. Indeed, the distortion may even change sign. Irrespective of whether both distortionary factors are present at once, the same pension contribution will thus discourage labour less if the 
scheme is Bismarckian, than if it is Beveridgean. In some circumstances it may even encourage labour.

\section{Individual decisions in the absence of a public pension scheme}

Let $l^{i}$ denote the labour, $c_{1}^{i}$ the working-age consumption, and $c_{2}^{i}$ the retirement-age consumption of agent $i$. His utility is assumed to be given by

$$
U^{i}=u_{1}\left(c_{1}^{i}-v\left(l^{i}\right)\right)+u_{2}\left(c_{2}^{i}\right),
$$

where $v\left(l^{i}\right)$ is the money-equivalent of the disutility of labour. The functions $u_{t}($.$) are assumed increasing and concave, and the function$ $v($.$) increasing and convex. The agent chooses \left(c_{1}^{i}, c_{2}^{i}, l^{i}, s^{i}\right)$ to maximize (1), subject to

$$
\begin{gathered}
c_{1}^{i}+s^{i}=w^{i} l^{i}, \\
c_{2}^{i}=s^{i} r
\end{gathered}
$$

and

$$
s^{i} \geq-b^{i},
$$

where $s^{i}$ denotes $i$ 's saving, $b^{i}$ his credit ration (positive or zero), $w^{i}$ his wage rate, and $r$ the market interest factor.

Substituting $(2)-(3)$ directly into the maximand, we can write the first-order conditions as

$$
v^{\prime}\left(l^{i}\right)=w^{i}
$$

and

$$
\frac{u_{1}^{\prime}\left(w^{i} l^{i}-v\left(l^{i}\right)-s^{i}\right)-\lambda}{u_{2}^{\prime}\left(r s^{i}\right)}=r,
$$

where $\lambda$ is the Lagrange-multiplier of (4).

\section{Stylized pension schemes}

Let us now introduce a compulsory pension scheme. The latter will reduce $i$ 's disposable income by the contribution $\theta^{i}$ while he is of working age, and increase it by the benefit $\eta^{i}$ when the agent is retired. The pension contribution is typically an increasing function of labour income, such that the marginal contribution rate is always less than 100 percent,

$$
\theta^{i}=\theta\left(w^{i} l^{i}\right), 0<\theta^{\prime}<1 .
$$

If the scheme is of the Beveridgean type, individual benefits may be the same for everyone, or vary with certain personal characteristics, but 
are in any case unrelated to individual contributions. We shall simply assume that

$$
\eta^{i}=\eta
$$

for all $i$. By contrast, if the scheme is Bismarckian, individual benefits will increase with individual contributions,

$$
\eta^{i}=\eta\left(\theta^{i}\right), \eta^{\prime}(.)>0 .
$$

A pension scheme is said to be actuarially fair if, at the time of retirement, the expected value of future benefits is equal to the capitalized value of the contributions made. ${ }^{1}$ In the absence of uncertainty, this simply means $\eta^{i}=\theta^{i} r$. If $i$ 's treatment is more than actuarially fair, $\eta^{i}>\theta^{i} r, i$ is getting a present from somebody. If it is less than actuarially fair, $\eta^{i}<\theta^{i} r$, either he is being obliged to make a present to someone, or the scheme is badly run.

The difference between the capitalized value of the contributions and the present value of the benefits constitutes an implicit tax,

$$
\vartheta^{i}=\theta^{i}-\frac{\eta^{i}}{r} .
$$

If (10) is negative, $-\vartheta^{i}$ is an implicit subsidy. In view of (7) - (8), if the scheme is Beveridgean, the implicit tax (subsidy) is increasing (decreasing) in individual earnings. The scheme is thus redistributive by nature. If the scheme is Bismarckian, by contrast, $\vartheta^{i}$ can increase, decrease or stay constant as $w^{i} l^{i}$ increases. Assuming that the government will not deliberately set out to take from low earners and give to high earners, we shall take it for granted that the implicit tax is non-decreasing in the pension contribution,

$$
\vartheta^{i}=\vartheta\left(\theta^{i}\right), \vartheta^{\prime}(.) \geq 0,
$$

and thus in earnings.

The marginal return to money paid into a Beveridgean scheme is always zero. In view of $(10)-(11)$, the marginal return to money paid into a Bismarckian one is given by

$$
\frac{d \eta^{i}}{d \theta^{i}}=\left[1-\vartheta^{\prime}\left(\theta^{i}\right)\right] r,
$$

equal to $r$ if the implicit tax does not vary with the amount of the contribution (in particular, if it is zero), lower (higher) if it grows faster (more slowly).

\footnotetext{
${ }^{1}$ In the present context, this is to interpreted as meaning that the actuarial value of future benefits is equal to the lump sum that the agent would get, at the date of retirement, if the cotributions were invested in a private fund, rather than paid into the public pension scheme. This lump sum will thus be net of the costs and normal profits of the private fund manager.
} 


\section{Labour implications of alternative pension schemes}

If the pension scheme is Beveridgean, the agent will supply labour to the point where the money-equivalent of the marginal disutility of labour equals the marginal increase in take-home pay,

$$
v^{\prime}\left(l^{i}\right)=\left[1-\theta^{\prime}\left(w^{i} l^{i}\right)\right] w^{i} .
$$

Comparing (13) with (5), it is clear that the scheme introduces a wedge between the wage rate and the marginal take-home pay. This will reduce the amount of labour supplied. Additionally, if the agent is not rationed in the credit market, the lump-sum benefit $\eta^{i}$ will have a negative income effect. Therefore, a Beveridgean pension scheme will discourage labour even if the agent happens to be fairly treated. ${ }^{2}$

If the scheme is Bismarckian, the marginal benefit of supplying labour is given by the increase in take-home pay, plus the increase in the currentconsumption equivalent of future pension benefits. Consider fist the case where the benefit formula is actuarially fair. The agent now supplies labour to the point where

$v^{\prime}\left(l^{i}\right)=\left[1-\left(1-\frac{r}{u_{1}^{\prime}\left(w^{i} l^{i}-v\left(l^{i}\right)-s^{i}-\theta^{i}\right) / u_{2}^{\prime}\left(s^{i} r+\eta\left(\theta^{i}\right)\right)}\right) \theta^{\prime}\left(w^{i} l^{i}\right)\right] w^{i}$.

If he is not credit rationed, his MRS is equal to $r$, and (14) simplifies to (5). There is then no tax wedge. Intuitively, that is because the pension contribution is not a tax on labour, but a postponed wage payment. In the absence of credit rationing, the agent is then indifferent between receiving a unit of money while he is working, or $r$ when he retires. In the presence of credit rationing, the expression in round brackets on the right-hand side of (14) is positive and lower than 1, because the agent's MRS is higher than $r$. The whole right-hand side of the equation is then smaller than $w^{i}$, but larger than $\left(1-\theta^{\prime}\right) w^{i}$. Therefore, an actuarially fair Bismarckian scheme does not distort labour decisions directly. It does, indirectly, if saving decisions are distorted by credit rationing. Even so, the tax wedge will be smaller than it would if the scheme were Beveridgean.

Next, consider the case where the benefit formula is not actuarially fair. The size of the increase in future pension benefits is now dependent

\footnotetext{
${ }^{2}$ In the absence of forced intergenerational transfers, this would be true of persons somewhere in the middle of the earnings distribution. Such transfers would occur at the earlier stages of the scheme if retirees were allowed to draw benefits without having contributed for a full working life, or at all. All members of the earlier cohorts would then get an implicit pension subsidy ("inaugural gains"), and many members of later cohorts would pay an implicit tax.
} 
on what happens to the implicit pension tax. Using (10), the first-order condition on the choice of $l^{i}$ may be written as

$v^{\prime}\left(l^{i}\right)=\left[1-\left(1-\frac{1-\vartheta^{\prime}\left(\theta^{i}\right)}{u_{1}^{\prime}\left(w^{i} l^{i}-v\left(l^{i}\right)-s^{i}-\theta^{i}\right) / u_{2}^{\prime}\left(s^{i} r+\eta\left(\theta^{i}\right)\right)} r\right) \theta^{\prime}\left(w^{i} l^{i}\right)\right] w^{i}$.

In the absence of credit rationing, (15) simplifies to

$$
v^{\prime}\left(l^{i}\right)=\left[1-\vartheta^{\prime}\left(\theta^{i}\right) \theta^{\prime}\left(w^{i} l^{i}\right)\right] w^{i} .
$$

There will then a tax wedge only if the implicit pension tax (subsidy) is increasing (decreasing) in labour income. In the presence of credit rationing, by contrast, there may be a tax wedge even if the implicit tax (subsidy) does not vary with earnings. It is clear from (15), however, that the distortion in the life-cycle allocation of consumption (MRS larger than $r$ ) reduces the size of the tax wedge. The marginal return to labour and the marginal return to money distortions tend to offset each other. Indeed, if it so happens that, for the agent in question, the implicit tax grows faster than the pension contribution $\left(\vartheta^{\prime}>1\right)$, the wedge may change sign. Rather than of wedge, we should then be talking of a premium. In any case, labour will still be discouraged less than it would if the scheme were Beveridgean. Notice, finally, that the sign of the distortion depends not on the sign, but on the rate of change of the implicit pension tax. Whether he is paying an implicit tax or receiving an implicit subsidy matters for the agent's utility and, if he is not credit rationed, for his saving, but not for his labour decision.

\section{A fairly common special case}

In real-life pension schemes, individual contributions are typically proportional to individual earnings,

$$
\theta^{i}=\tau w^{i} l^{i}, 0<\tau<1 .
$$

In continental Europe, the tendency is to set benefits at the actuarially fair level if this does not fall short of a certain minimum $\eta_{0}$, and does not exceed a certain maximum $\eta_{1}$. Floor and ceiling tend to be set so that the implicit taxes extracted from very high earners are sufficient to pay for the implicit subsidies given to very low earners. Therefore,

$$
\begin{gathered}
\eta^{i}=r \tau w^{i} l^{i} \text { for } \eta_{0}<r \tau w^{i} l^{i}<\eta_{1}, \\
\eta^{i}=\eta_{0} \text { for } r \tau w^{i} l^{i} \leq \eta_{0}
\end{gathered}
$$

and

$$
\eta^{i}=\eta_{1} \text { for } r \tau w^{i} l^{i} \geq \eta_{1}
$$


The scheme in question is effectively Beveridgean for the minority of workers at either end of the earnings distribution, Bismarckian (and actuarially fair) for the great majority in the middle. In view of (10) and $(18)-(19)$, the marginal tax rate $\vartheta^{\prime}$ is equal to unity for people in the tails of the distribution, to zero for everybody else. We shall use this scheme to illustrate the effects of the contribution rate on the amount of labour supplied.

For $w^{i} l^{i}$ lower than $\eta_{0} / \tau r$ or higher than $\eta_{1} / \tau r$, the choice of $l^{i}$ satisfies

$$
v^{\prime}\left(l^{i}\right)=(1-\tau) w^{i} .
$$

The effect of a small change in $\tau$ is then

$$
\frac{d l^{i}}{d \tau}=-\frac{w^{i}}{v^{\prime \prime}\left(l^{i}\right)}
$$

clearly negative, and increasing in size with $w^{i}$. Therefore, the policy will discourage labour for very high wage earners, hardly at all for very low ones.

For $w^{i} l^{i}$ comprised between $\eta_{0} / \tau r$ and $\eta_{1} / \tau r$, the effect of $\tau$ on $l^{i}$ depends on whether $i$ is credit rationed or not. If he is not, $\tau$ has no effect on the amount worked. If he is, the choice of $l^{i}$ satisfies

$$
\left[(1-\tau) w^{i}-v^{\prime}\left(l^{i}\right)\right] u_{1}^{\prime}\left((1-\tau) w^{i}-v\left(l^{i}\right)-s^{i}\right)+r \tau w^{i} u_{2}^{\prime}\left(r s^{i}+r \tau w^{i} l^{i}\right)=0
$$

which may also be written as

$$
(1-\tau) w^{i}-v^{\prime}\left(l^{i}\right)=-\frac{r \tau w^{i}}{u_{1}^{\prime}\left((1-\tau) w^{i}-v\left(l^{i}\right)-s^{i}\right) / u_{2}^{\prime}\left(r s^{i}+r \tau w^{i} l^{i}\right)} .
$$

The effect of a small change in the contribution rate is then

$$
\frac{d l^{i}}{d \tau}=-\frac{u_{1}^{\prime}+\left[(1-\tau) w^{i}-v^{\prime}\left(l^{i}\right)\right] l^{i} u_{1}^{\prime \prime}-r^{2} \tau w^{i} u_{2}^{\prime \prime}}{v^{\prime \prime}\left(l^{i}\right) u_{1}^{\prime}+\left[(1-\tau) w^{i}-v^{\prime}\left(l^{i}\right)\right] v^{\prime}\left(l^{i}\right) u_{1}^{\prime \prime}-r^{2} \tau^{2}\left(w^{i}\right)^{2} u_{2}^{\prime \prime}} w^{i} .
$$

In view of (23), it is clear that (24) has ambiguous sign. However, the more stringent is the credit ration (the higher the MRS relative to $r$ ), the more positive, or less negative, will be the effect of $\tau$ on $l^{i}$. The aggregate effect is minimized if $\tau$ is set no higher than the aggregate saving rate in the absence of policy.

\section{Conclusion}

The answer to the question in the title is that a pension scheme will necessarily insert a wedge between the wage rate and the marginal takehome pay only if the scheme is Beveridgean. If that is the case, the 
policy will necessarily discourage labour. If the scheme is Bismarckian, by contrast, there can be a wedge only if the benefit formula is not actuarially fair, or if the worker is credit rationed. If the formula is not actuarially fair, and the worker is credit rationed, the two distortions will tend to offset each other, and the wedge will be smaller than it would be if the scheme were Beveridgean. Indeed, if the implicit tax grows faster than the pension contribution $\left(\vartheta^{\prime}>1\right)$, the wage distortion may change sign. In general, therefore, a Bismarckian scheme will always discourage labour less than a Beveridgean scheme, and may even encourage it. If the scheme is Bismarckian and actuarially fair for all workers earning more than a certain minimum, and less than a certain maximum, as in many parts of continental Europe, labour can be seriously discouraged only for very high earners.

\section{References}

Alesina, A. and R. Perotti (1997), Welfare State and Competitiveness, American Economic Review 61, 477-494

Börsch-Supan, A. and A. Reil-Held (2001), How Much is Transfer and How Much is Insurance in a Pay-as-You-Go System? The German Case, Scandinavian Journal of Economics 103, 507-526

Disney, R. (2004), Are Contributions to Public Pension Programmes a Tax on Employment?, Economic Policy, July 2004, 269-311

Fenge, R. and M. Werding (2004), Ageing and the Tax Implied in Public Pension Schemes: Simulations for Selected OECD Countries, Fiscal Studies 25, 159-200

Lüdeke, R. (1988), Staatsverschuldung, Intragenerative Redistribution und Umlagefinanzierte Rentenversicherung, in J. Klaus and P. Klemmer (eds.), Wirtschaftliche Strukturprobleme und Soziale Fragen, Berlin: Duncker \& Humblot, 167-181

Murphy, K. and F. Welch (1998), Perspectives on the Social Security Crisis and Proposed Solutions, American Economic Review 88, 142-150

Orszag, P. and J. E. Stiglitz (2000), Rethinking Pension Reform: Ten Myths About Social Security Systems, in: R. Holzmann and J. E. Stiglitz (eds.), New Ideas About Old Age Security: Toward Sustainable Systems, Washington D.C.: The World Bank, 17-56

Scarpetta, S. (1996), Assessing the Role of Labour Market Policies and Institutional Settings on Unemployment: A Cross-Section Study, OECD Economic Studies 26

Sinn, H.-W. (1990), Korreferat zum Referat von K. Jaeger, in B. Gahlen, H. Hesse and H. J. Ramser (eds.), Theorie und Politik der Sozialversicherung, Tübingen: Mohr-Siebeck, 99-101

Tullio, G. (1987), Long-Run Implications of the Increase in Taxa- 
tion and Public Debt for Employment and Economic Growth in Europe, European Economic Review 31, 741-780 